\title{
Exploring the role of Honesty-Humility in replicating "The relationships between behavioral addictions and the five-factor model of personality"
}

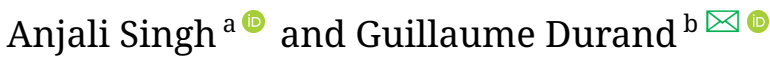 \\ ${ }^{a}$ School of Business and Management Studies, Department of Management Studies, Central University of Haryana, India \\ ${ }^{\mathrm{b}}$ School of Counselling, Psychotherapy and Spirituality, Faculty of Human Sciences, Saint Paul University, Ottawa, Canada
}

\begin{abstract}
This study is a replication of Andreassen and colleagues (2013) [The relationships between behavioral addictions and the five-factor model of personality. Journal of Behavioral Addictions, 2(2), 90-99]. We partially replicated the findings of the original study. Our results support the role of personality, particularly conscientiousness, in predicting behavioral addictions, such as video game, Internet, and mobile phone addiction. However, we failed to replicate the same pattern of personality traits for each behavioral addiction.
\end{abstract}

Keywords • Big-five; HEXACO; Behavioral addiction; Internet addiction; General population.
Acting Editor $n$ Denis Cousineau (Université d'Ottawa)

Reviewers

- No authors from the original study reviewed this replication study

\section{Introduction}

Addiction is commonly defined as a persistent condition derived from engaging in a specific behavior due to an unhealthy motivation (West \& Brown, 2013). While addiction has been extensively studied from a biological perspective, the notion of behavioral addiction is relatively recent (Alavi et al., 2012). Peele and Broodsky (1979) theorized that an individual could become an addict without chemical substances. According to them, anyone who is dependent to specific behaviors or experiences would be considered addicted. Subsequently, researchers started investigating how behaviors commonly known to be excessive in some individuals, such as browsing internet, playing video games, and doing physical activities could have a negative impact on people (Alavi et al., 2012). It is important to note that enjoying those activities in abundance does not warrant a diagnosis of addiction. Indeed, there is a consensus that a persistent behavior will be considered an addiction if it results in severe negative impacts in social situations or relationships, or work (Widyanto \& Griffiths, 2006).

Among the numerous factors related to behavioral addictions, personality traits have been suggested to be associated with addiction, particularly internet-related addictions (Weibel, Wissmath, \& Groner, 2010). Multiple studies examined the relationship between internet addiction and the big-five personality traits. These traits include openness, conscientiousness, extraversion, agreeableness, and neuroticism (i.e., sometimes referred to as emotionality) (John \& Srivastava, 1999). A meta-analytic review performed by Kayis et al. (2016) suggested that openness, conscientiousness, extraversion, and agreeableness were negatively associated with internet addiction, while neuroticism was positively associated with internet addiction.

Behavioral addictions, as well as internet addictions, can be considered umbrella terms including multiple subcategories. A study by Andreassen et al. (2013) investigated the relationship between the big-five personality traits and subcategories of behavioral and internet addictions (i.e., Facebook addiction, video game addiction, Internet addiction, physical exercise addiction, mobile phone addiction, compulsive buying, and studying addiction). Their results suggested that neuroticism was positively associated with addictions derived from using internet, exercising, and compulsive buying and study. Similar results were found regarding extraversion, which was positively associated with excessive use of Facebook and mobile phone, as well as compulsive buying and exercising. Alternatively, openness and agreeableness were negatively associated with multiple addictions. Consciousness had mitigating results, 
being negatively associated with excess in Facebook usage, video game, Internet, and compulsive buying, but was positively associated with exercise and studying addiction.

The purpose of the present study is to replicate the decade old findings of Andreassen et al. (2013) and examine the external validity in the general population. Indeed, considering the original study focused on 218 Norwegian university students, this replication study will recruit participants from the general public.

\section{Methods}

\section{Participants}

Participants ( $N=225$ ) were recruited on the social media reddit.com/r/samplesize; a website serving as a pool of participants for academic research. The sample included 136 females, 89 males. Most participants were in North America (58\%) or Europe (30\%). Approximately a third (34\%) of the participants were currently enrolled as a full-time student in a university. The mean age of the participants was 27.22 years old $(S D=9.06)$.

\section{Materials and Procedures}

The procedure of this replication study was the same as the one used by Andreassen et al. (2013), albeit with a few differences. First, we replaced the NEO-Five-Factor Inventory-Revised from McCrae and Costa (2004) by the HEXACO (Ashton \& Lee, 2009). The HEXACO is a measure of the big-six; the five original constructs (i.e., neuroticism, extraversion, agreeableness, conscientiousness, and openness) and adds an original factor, namely honestyhumility. The HEXACO is a reliable and well validated measure of personality traits and has been used extensively in psychological research (Ashton, Lee, \& de Vries, 2014; Lee \& Ashton, 2004, 2018). Second, the authors used the 13-item version of the Compulsive Buying Scale (CBS), which is derived from the items of a questionnaire originally developed by Young (1998). We used an updated version of the CBS including 16 items (Maraz et al., 2015). The Bergen Facebook Addiction Scale (BFAS; Andreassen, Griffiths, Hetland, \& Pallesen, 2012), the Game Addiction Scale for Adolescents (GASA; Lemmens, Valkenburg, \& Peter, 2009), the Young's Diagnostic Questionnaire (YDQ - a measure of internet addiction; Young, 1998), the Exercise Addiction Inventory (EAI; Terry, Szabo, \& Griffiths, 2004), the Mobile Phone Addiction Index (MPAI; Leung, 2008), and the Study Addiction Scale (SAS; Andreassen et al., 2012) remained unchanged from the original study and used the same modifications (e.g., using a 5-point scale for the YDQ). Participants were not compensated in the original and the current study.

\section{Results}

The reliability of each scale as well as the correlation between all the variables are presented in Table 1. Overall, Facebook addiction and videogame addiction were associated with internet addiction, mobile phone addiction and compulsive buying. Internet addiction was associated with mobile phone addiction and compulsive buying. Lastly, mobile phone addiction was associated with compulsive buying. Subsequently, regression analyses were performed on the seven types of addictive behaviors (Table 2).

Facebook addiction. Regression analysis failed to identify a significant model in Step $1(F(2,222)=6.494, p=$ $.002)$ and Step $2(F(8,216)=2.384, p=.018)$.

Video game addiction. Regression analysis failed to identify a significant model in Step $1(F(2,222)=3.993$, $p=.020)$, but supported the model of Step $2(F(8,216)=$ $6.447, p<.001)$. The second model explained $16.3 \%$ of the variance. Out of the included predictors, only conscientiousness ( $\beta=-.329$ ) was significant at $p<.001$.

Internet addiction. Regression analysis identified a significant model in Step $1(F(2,222)=11.192, p=.001)$ and in Step $2(F(8,216)=9.745, p<.001)$. The first model explained $8.3 \%$ of the variance with only sex as a significant predictor ( $\beta=.237$ ). The second model explained $23.8 \%$ of the variance with emotionality and conscientiousness being the significant predictors ( $\beta=.218$ and -.299 ) respectively.

Exercise addiction. Regression analysis failed to identify a significant model in Step $1(F(2,222)=1.185, p=.308)$ and in Step $2(F(8,216)=2.147, p=.033)$.

Mobile phone addiction. Regression analysis identified a significant model in Step $1(F(2,215)=15.687, p<.001)$ and in Step $2(F(6,209)=14.017, p<.001)$. In the first model, both the predictors sex and age were significant at the $p<.001$ ( $\beta=.289$ and -.229 ). The model explained $11.9 \%$ of the variance. In the second model, honesty-humility ( $\beta=-.261$ ), emotionality $(\beta=.331$ ), and conscientiousness ( $\beta=-.237$ ) were significant predictors. The model explained $32.4 \%$ of the variance.

Compulsive buying. Regression analysis successfully identified a significant model in Step $1(F(2,222)=8.447$, $p=.048)$ with sex as a predictor $(\beta=.262, p<.001)$. The model was able to explain $6.2 \%$ of the variance. The second model was also identified as a significant in Step 2 $(F(8,216)=11.072, p<.001)$. Emotionality and conscientiousness ( $\beta=.338$ and -.241 ) were significant predictors. The model explained $26.5 \%$ of the variance.

Study addiction. To correct for the smaller sample size of students, a threshold of $p \leq .01$ was used to establish significance. Regression analysis failed to identify a significant model in Step $1(F(2,91)=.892, p=.413)$, but 
Table 1 - Reliability and correlations between the variables of the study

\begin{tabular}{|c|c|c|c|c|c|c|c|c|c|c|c|c|c|c|}
\hline Variable & 2 & 3 & 4 & 5 & 6 & 7 & 8 & 9 & 10 & 11 & 12 & 13 & 14 & 15 \\
\hline 1. Sex & .07 & -.02 & .38 & -.13 & -.11 & -.04 & -.01 & .22 & -.03 & .22 & -.10 & .27 & .26 & .04 \\
\hline 2. Age & & .28 & -.05 & 18 & .15 & .27 & .15 & 11 & -.19 & -.19 & -.03 & -.21 & -.05 & -.13 \\
\hline 3. Honesty-Humility & & $(.76)$ & -.08 & -.01 & 39 & 20 & -.03 & -.05 & -.23 & -.21 & .01 & -.36 & -.26 & -.09 \\
\hline 4. Emotionality & & & $(.82)$ & -.22 & -.14 & -.01 & .08 & .19 & .16 & .31 & -.07 & 40 & 39 & .22 \\
\hline 5. Extraversion & & & & $(.82)$ & 14 & 34 & .36 & -.01 & -.14 & -.23 & .20 & -.12 & -.20 & -.01 \\
\hline 6. Agreeableness & & & & & $(.81)$ & .05 & -.06 & -.06 & -.07 & -.18 & .13 & -.19 & -.15 & -.24 \\
\hline 7. Conscientiousness & & & & & & $(.80)$ & .16 & .02 & -.37 & -.36 & .03 & -.30 & -.28 & .30 \\
\hline 8. Openness & & & & & & & $(.81)$ & .10 & -.05 & .03 & -.05 & .02 & -.11 & .02 \\
\hline 9. Facebook addiction & & & & & & & & $(.89)$ & .01 & .25 & -.02 & .29 & .24 & .10 \\
\hline 10. Video $g$ & & & & & & & & & $(.87)$ & .42 & .06 & .38 & .32 & -.16 \\
\hline $\mathrm{t}$ addiction & & & & & & & & & & $(.86)$ & .06 & .72 & .33 & .15 \\
\hline 12. Exercise addiction & & & & & & & & & & & $(.78)$ & .08 & -.05 & .13 \\
\hline 13. Mobil & & & & & & & & & & & & $(.88)$ & .43 & .13 \\
\hline 14. Com & & & & & & & & & & & & & $(.93)$ & .08 \\
\hline 15. Study addiction & & & & & & & & & & & & & & $(.79)$ \\
\hline
\end{tabular}

Note. Bold indicates $p \leq .001$. All variables at $N=225$ at the exception of Mobile phone addiction $(N=218)$ and Study addiction $(N=94)$. Cronbach's alphas are in parenthesis.

identified a significant model in Step $2(F(8,85)=3.077$, $p=.002$ ). The second model predicted $15.2 \%$ of the variance, with conscientiousness being the only predictor $(\beta=.376, p=.001)$.

\section{Discussion}

Overall, the results of this replication study partly replicate the findings of Andreassen et al. (2013). Results from the Pearson correlations suggest that 1) emotionality (neuroticism) is positively associated with Internet and mobile phone addiction, as well as compulsive buying, 2) extraversion, agreeableness, and openness are unrelated to behavioral addiction, at the exception of a weak negative associ- ation between extraversion and internet addiction, 3) conscientiousness and honesty-humility are negatively associated with video game and mobile phone addiction, as well as compulsive buying. Conscientiousness was also associated with internet addiction. Taken altogether, the results support previous findings regarding the association between emotionality and conscientiousness on behavioral addictions but fails to support the previous conclusions regarding the associations between extraversion, agreeableness, and openness on behavioral addictions. These divergent findings may be due to the threshold used to establish significance. Indeed, to correct for potential type I error, the present study established significance at .001 , while the

Table 2 - Results of multiple regression analyses

\begin{tabular}{|c|c|c|c|c|c|c|c|c|c|c|c|c|c|c|}
\hline & \multicolumn{2}{|c|}{$\begin{array}{l}\text { Facebook } \\
\text { addiction }\end{array}$} & \multicolumn{2}{|c|}{$\begin{array}{l}\text { Video game } \\
\text { addiction }\end{array}$} & \multicolumn{2}{|c|}{$\begin{array}{l}\text { Internet ad- } \\
\text { diction }\end{array}$} & \multicolumn{2}{|c|}{$\begin{array}{l}\text { Exercise ad- } \\
\text { diction }\end{array}$} & $\begin{array}{l}\text { Mobile } \\
\text { phone } \\
\text { diction }\end{array}$ & \multirow{2}{*}{$\frac{\text { ad- }}{\beta}$} & \multicolumn{2}{|c|}{$\begin{array}{l}\text { Compulsive } \\
\text { buying }\end{array}$} & \multicolumn{2}{|c|}{$\begin{array}{l}\text { Study addic- } \\
\text { tion }\end{array}$} \\
\hline Predictors & $\Delta R^{2}$ & $\beta$ & $\Delta R^{2}$ & $\beta$ & $\Delta R^{2}$ & $\beta$ & $\Delta R^{2}$ & $\beta$ & $\Delta R^{2}$ & & $\Delta R^{2}$ & $\beta$ & $\Delta R^{2}$ & $\beta$ \\
\hline Step 1 & .047 & & .026 & & .083 & & .002 & & .119 & & .062 & & -.002 & \\
\hline Sex & & .209 & & -.016 & & .237 & & -.098 & & .289 & & .262 & & .048 \\
\hline Age & & .096 & & -.185 & & -.204 & & -.025 & & -.229 & & -.066 & & -.133 \\
\hline Step 2 & .047 & & .163 & & .238 & & .039 & & .324 & & .265 & & .152 & \\
\hline Sex & & .158 & & -.109 & & .116 & & -.064 & & .146 & & .106 & & -.035 \\
\hline Age & & .113 & & -.041 & & -.069 & & -.057 & & -.077 & & .105 & & -.172 \\
\hline Honesty-Humility & & -.057 & & -.144 & & -.085 & & -.015 & & -.261 & & -.205 & & -.024 \\
\hline Emotionality & & .122 & & .184 & & .218 & & .023 & & .331 & & .338 & & .193 \\
\hline Extraversion & & -.006 & & -.002 & & -.083 & & .241 & & .061 & & -.003 & & -.039 \\
\hline Agreeableness & & -.016 & & .018 & & -.062 & & .105 & & -.008 & & -.020 & & -.196 \\
\hline Conscientiousness & & .001 & & -.329 & & -.299 & & -.023 & & -.237 & & -.241 & & .376 \\
\hline Openness & & .077 & & -.006 & & .095 & & -.124 & & .009 & & -.121 & & -.024 \\
\hline
\end{tabular}

Note. Bold indicates $p \leq .001 . \Delta R^{2}=$ adjusted $R^{2} ; \beta=$ standardized beta. All regressions used the enter method. 
study by Andreassen et al. (2013) established significance at .05 and .01 .

A similar outcome was identified when comparing the results of the regression analyses. The present study failed to replicate the findings regarding Facebook addiction and exercise addiction. We also failed to identify biological sex as a significant predictor in all behavioral addictions once taking personality traits into account. Past studies suggested that males tend to display higher levels of Internet addiction than females (Li, Hou, Yang, Jian, \& Wang, 2019). It is possible that the lack of significant result is due to the focus on biological sex rather than gender. Indeed, future studies should focus on exploring potential differences between gender and biological sex on the impact between personality and addiction.

Despite these inconclusive findings, we found support for the role of personality on video game, Internet, and mobile phone addiction, as well as compulsive buying, and to a lesser degree study addiction. We replicated previous findings regarding the predictive role of conscientiousness on video game and Internet addiction. Regarding mobile phone addiction, the original study identified extroversion, openness, and agreeableness as significant predictors, while our study identified conscientiousness and emotionality, as well as honesty-humility, as significant predictors. Lastly, emotionality and conscientiousness were the only significant predictors of compulsive buying in our study, while all traits but openness were significant predictors in the original study.

In conclusion, our study supports the notion that specific personality traits are associated with behavioral addictions. We also support the predictive value of some personality traits on behavioral addiction, with explained variance varying from $6 \%$ to $32.2 \%$ (as opposed to $6 \%$ to $17 \%$ in the original study). However, we failed to replicate the exact pattern of traits on each behavioral addiction. While personality traits from the big-five may partially explain behavioral addiction, their relative contribution in explaining the study's variables may be too small to be detected without including other variables, such as motivation and self-control.

\section{References}

Alavi, S. S., Ferdosi, M., Jannatifard, F., Eslami, M., Alaghemandan, H., \& Setare, M. (2012). Behavioral addiction versus substance addiction: Correspondence of psychiatric and psychological views. International Journal of Preventive Medicine, 3(4), 290-294.

Andreassen, C. S., Griffiths, M. D., Gjertsen, S. R., Krossbakken, E., Kvam, S., \& Pallesen, S. (2013). The relationships between behavioral addictions and the five- factor model of personality. Journal of Behavioral Addictions, 2(2), 90-99. doi:10.1556/JBA.2.2013.003

Andreassen, C. S., Griffiths, M. D., Hetland, J., \& Pallesen, S. (2012). Development of a work addiction scale. Scandinavian Journal of Psychology, 53(3), 265-272. doi:10. 1111/j.1467-9450.2012.00947.x

Ashton, M. C., \& Lee, K. (2009). The hexaco-60: A short measure of the major dimensions of personality. Journal of Personality Assessment, 91(4), 340-345. doi:10.1080/ 00223890902935878

Ashton, M. C., Lee, K., \& de Vries, R. E. (2014). The hexaco honesty-humility, agreeableness, and emotionality factors: A review of research and theory. Personality and Social Psychology Review?: An Official Journal of the Society for Personality and Social Psychology, Inc, 18(2), 139-152. doi:10.1177/1088868314523838

John, O. P., \& Srivastava, S. (1999). The big five trait taxonomy: History, measurement, and theoretical perspectives. Handbook of Personality: Theory and Research, 2(510), 102-138.

Kayis, A. R., Satici, S. A., Yilmaz, M. F., Simsek, D., Ceyhan, E., \& Bakioglu, F. (2016). Big five-personality trait and internet addiction: A meta-analytic review. Computers in Human Behavior, 63, 35-40. doi:10.1016/j.chb. 2016.05.012

Lee, K., \& Ashton, M. C. (2004). Psychometric properties of the hexaco personality inventory. Multivariate Behavioral Research, 39(2), 329-358. doi:10.1207/ s15327906mbr3902

Lee, K., \& Ashton, M. C. (2018). Psychometric properties of the hexaco-100. Assessment. 25(5), 543-556. doi:10. 1177/1073191116659134

Lemmens, J. S., Valkenburg, P. M., \& Peter, J. (2009). Development and validation of a game addiction scale for adolescents. Media Psychology, 12(1), 77-95. doi:10 . 1177/1073191116659134

Leung, L. (2008). Linking psychological attributes to addiction and improper use of the mobile phone among adolescents in hong kong. Journal of Children and Media, 2(2), 93-113. doi:10.1080/17482790802078565

Li, G., Hou, G., Yang, D., Jian, H., \& Wang, W. (2019). Relationship between anxiety, depression, sex, obesity, and internet addiction in chinese adolescents: A short-term longitudinal study. Addictive Behaviors, 90, 421-427. doi:10.1016/j.addbeh.2018.12.009

Maraz, A., Eisinger, A., Hende, B., Urbán, R., Paksi, B., Kun, B., ... Demetrovics, Z. (2015). Measuring compulsive buying behaviour: Psychometric validity of three different scales and prevalence in the general population and in shopping centres. Psychiatry Research, 225(3), 326-334. doi:10.1016/j.psychres.2014.11.080 
McCrae, R. R., \& Costa, P. T. (2004). A contemplated revision of the neo five-factor inventory. Personality and Individual Differences, 36(3), 587-596. doi:10.1016/S01918869(03)00118-1

Peele, S., \& Broodsky, A. (1979). Love and addiction. New York: Taplinger.

Terry, A., Szabo, A., \& Griffiths, M. (2004). The exercise addiction inventory: A new brief screening tool. Addiction Research and Theory, 12(5), 489-499. doi:10.1080/ 16066350310001637363

Weibel, D., Wissmath, B., \& Groner, R. (2010). Motives for creating a private website and personality of per- sonal homepage owners in terms of extraversion and heuristic orientation. Cyberpsychology: Journal of Psychosocial Research on Cyberspace, 4(1), 1-10.

West, R., \& Brown, J. (2013). Theory of addiction. doi:10 . $1002 / 9781118484890$

Widyanto, L., \& Griffiths, M. (2006). Internet addiction: A critical review. International Journal of Mental Health and Addiction, 4(1), 31-51. doi:10.1007/s11469-0069009-9

Young, K. S. (1998). Internet addiction: The emergence of a new clinical disorder. Cyberpsychology and Behavior, 1(3), 237-244. doi:10.1089/cpb.1998.1.237

\section{Citation}

Singh, A., \& Durand, G. (2022). Exploring the role of honesty-humility in replicating "the relationships between behavioral addictions and the five-factor model of personality”. The Quantitative Methods for Psychology, 18(1), r1-r5. doi:10. 20982/tqmp.18.1.r001

Copyright (C 2022, Singh and Durand. This is an open-access article distributed under the terms of the Creative Commons Attribution License (CC BY). The use, distribution or reproduction in other forums is permitted, provided the original author(s) or licensor are credited and that the original publication in this journal is cited, in accordance with accepted academic practice. No use, distribution or reproduction is permitted which does not comply with 